\title{
Common European Framework of Reference for Language (CEFR) and Test of Proficiency in Korean (TOPIK)
}

Abstract (in English): This paper is an overview of Test of Proficiency in Korean (TOPIK). Test of Proficiency in Korean (TOPIK) is a test to measure and evaluate the Korean language proficiency targeting for overseas Koreans and foreigners who do not speak Korean as their first language. The TOPIK is utilized for studying in Korean universities or taking advantages of employment. Systems of the TOPIK are largely divided into TOPIK I and TOPIK II : TOPIK I is divided into the Beginner 1 and 2; TOPIK $\Pi$ is divided into Intermediate 1, 2, Advanced 1, and 2, all of which are equal to the measure proposed in the European common reference standard. Common European Framework of Reference (CEFR) is equipped with a six-step framework for language proficiency and communicative activities. This system describes knowledge, skills, cultural competence, and regulations of each step-by-step learning skill level for the purpose of communication in the private, public, and occupational areas.

This paper first presents the Common European Framework of Reference (CEFR) that is familiar to Europeans, and compares it with the TOPIK system. First, it compares the TOPIK with the Common European Framework of Reference on the overall system, the assessment method, question types and etc. Also, it briefly examines foreign language education in Korea. Foreign language education in Korea was in abstract level as compared to the Common European Framework of Reference or topic.

As in Europe, Korea also divides the language acquisition into 6 levels. It prepares the evaluation criteria for each level. Criteria and test methods can be understood by comparing the German language test and TOPIK to be carried out in accordance with the Common European Framework of Reference. Test methods and criteria of the German test and TOPIK are similar, but information and instruction for testing showed at the Goethe-Institute is far more detailed than TOPIK in Korea. The problem lies in the absence of speaking test in TOPIK. In order to understand the language proficiency, speaking, listening, reading and writing in all parts should be evaluated; however, there is no speaking test in TOPIK, and it is unfortunate that there is no writing test in the beginner-level test. This is what should be improved in the future.

Abstract (in Korean): 이 논문은 한국어능력시험 (Test of Proficiency in Korean, TOPIK) 에 대해 개관한 것이다. 한국어능력시험은 한국어를 모국어로 하지 않는 재외동포 및 외국인을 대상으로 한국어사용능력을 측정하고 평가하는 시험이다. 그리고 그 평가결과를 활용하여 국내 대학기관에 유학하거나 취업에 활용하고 있다. 토픽의 
체계는 크게는 TOPIK I 과 TOPIK II 로 나뉘고 다시 TOPIK I 은 초급 1, 2, TOPIK II 는 중급 1,2 , 고급 1,2 로 나뉘어 유럽공통참조기준에서 제시한 척도와 동일하다. 유럽공통참조기준은 의사소통활동과 언어능력수준을 기술하기 위한 여섯 단계로 체계가 갖춰져 있다. 이 체계는 개인, 공공, 직업영역에서 의사소통을 목적으로 언어를 사용하기 위해서 학습자가 배워야 하는 언어행위와 그 행위를 개발해야 하는 지식과 기능 및 문화적 능력을 기술하고 있으며, 각 학습단계별 능력수준을 규정하고 있다.

본고에서는 유럽인들에게 익숙한 유럽공통참조기준을 먼저 제시하고 이를 TOPIK 의 체제와 비교하였다. 그리고 한국어능력시험에 대한 전반적인 체제와 평가방법, 문항유형 등을 유럽공통참조기준과 비교하여 살펴보았다. 유럽에서와 마찬가지로 한국에서도 언어수준의 등급을 6 등급으로 나누었고, 각 수준에 맞는 평가기준을 마련하였다. 한 가지 문제점은 토픽에서는 말하기시험이 없다는 것이다. 한 사람의 언어능력을 파악하기 위해서는 말하기, 듣기, 읽기, 쓰기의 모든 영역에서 수준을 평가해야 하는데 아직까지 말하기시험이 없고, 초급에서 쓰기시험이 빠졌다는 것이 아쉬운 점이다. 이는 앞으로 개선해야 할 점이다.

Keyword: Test of Proficiency in Korean (TOPIK), Common European Framework of Reference for Language (CEFR), Korean as foreign language, Assessment of Korean

\section{Introduction}

Due to the fact that the interest in South Korea has increased in recent years in the world, the number of the Korean language learners has been growing. Korean learners, under the influence of the Korean Wave, learn the Korean language through Korean dramas and K-Pop, or they learn Korean culture and language through Korean distribution institutes, such as King Sejong Institute, the Hangul School, or Korean Council. Currently, for those with Korean as a foreign language, like Europeans, TOPIK, which is divided into Beginner, Intermediate, and Advanced levels, is required in order to enter college or get a job in Korea.

TOPIK is a test to measure and evaluate the Korean proficiency targeting for overseas Koreans and foreigners who do not speak Korean as their first language. Systems of the TOPIK are largely divided into TOPIK I and TOPIK $\Pi$ : TOPIK $I$ is divided into the entry 1 and 2; TOPIK $\Pi$ is divided into Intermediate 1, 2, Advanced 1, and 2, all of which are equal to the measure proposed in the European common reference standard.

Common European Framework of Reference is equipped with a six-step framework for language proficiency and communicative activities. This system describes knowledge, skills, cultural competence, and regulations of each step-by-step learning skill level for the purpose of communication in private, public, and occupational areas.

This paper first presents the Common European Framework of Reference that is familiar to Europeans, and compares it with the TOPIK system. Also, 
this should become the cornerstone to set the direction of the Korean education for those who are interested in the Korean language and who take the Test of Proficiency in Korean.

\section{Systematic comparison of the Common European Framework of Reference (CEFR) and TOPIK}

CEFR proposes a classification following the steps of the language evaluation from the A, B, and C. (Council of Europe 1997, p.32)

This step-by-step classification applies to Korean in the same way. TOPIK is divided into basic (beginner), independent (intermediate) and proficient

A

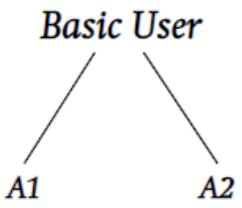

(Breakthrough) (Waystage)
B

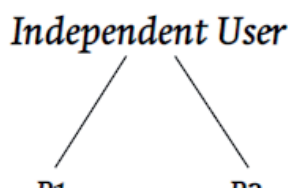

B1

(Threshold)
B2

(Vantage)
C

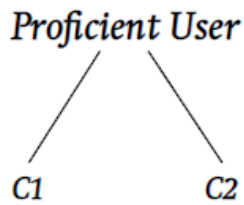

(Effective

Operational

Proficiency)

(advanced) user, and then each level is divided into two, making six levels in total.

The first TOPIK was conducted in 1997, and its latest 41st test was conducted in September 2015. However, early TOPIK had different types of question and evaluation criteria than the recent Korean Proficiency Test had. From 1 st to $9^{\text {th }}$ test, TOPIK was conducted by six grades system; beginner, intermediate, and advanced were divided into 1st grade, 2 nd grade, 3 rd grade, 4 th grade, 5th grade, and 6th grade. From the $10^{\text {th }}$ test, TOPIK had been reorganized into three grades; Beginner, Intermediate, and Advanced, and the score that rated the grade was based on the score obtained from the test. The system of TOPIK has been revised from 35th again. Current test is divided into TOPIK 1 and TOPIK 2, introducing the scores again and giving it a rating of 6 grades from 1 st to 6 th grade. 


\begin{tabular}{|c|c|c|c|}
\hline \multicolumn{2}{|c|}{ Korean Language } & \multicolumn{2}{c|}{ CEFR } \\
\hline \multirow{3}{*}{ TOPIK II } & 6th grade & C2 & \multirow{2}{*}{ Proficient User } \\
\cline { 2 - 3 } & 5th grade & C1 & \\
\cline { 2 - 3 } & 4th grade & B2 & \multirow{2}{*}{ Independent User } \\
\cline { 2 - 3 } & 3rd grade & B1 & Basic User \\
\hline \multirow{2}{*}{ TOPIK I } & 2nd grade & A2 & A1 \\
\cline { 2 - 3 } & 1st grade & A & \\
\hline
\end{tabular}

$<$ Table 1> Language proficiency system of Korea and the European Each step of a general measure of the CEFR is as follows: (Council of Europe 1997, p.33)

\section{A1}

Can understand and use familiar everyday expressions and very basic phrases aimed at the satisfaction of needs of a concrete type. Can introduce $\mathrm{him} /$ herself and others and can ask and answer questions about personal details such as where he/she lives, people he/she knows and things he/she has. Can interact in a simple way provided the other person talks slowly and clearly and is prepared to help.

\section{A2}

Can understand sentences and frequently used expressions related to areas of most immediate relevance (e.g. very basic personal and family information, shopping, local geography, employment). Can communicate in simple and routine tasks requiring a simple and direct exchange of information on familiar and routine matters. Can describe in simple terms aspects of his/her background, immediate environment and matters in areas of immediate need.

\section{B1}

Can understand the main points of clear standard input on familiar matters regularly encountered in work, school, leisure, etc. Can deal with most situations likely to arise whilst travelling in an area where the language is spoken. Can produce simple connected text on topics which are familiar or of personal interest. Can describe experiences and events, dreams, hopes and ambitions and briefly give reasons and explanations for opinions and plans.

\section{B2}

Can understand the main ideas of complex text on both concrete and abstract topics, including technical discussions in his/her field of specialization. Can interact with a degree of fluency and spontaneity that makes regular interaction with native speakers quite possible without strain for either party. Can produce clear, detailed text on a wide range of subjects and explain a viewpoint on a topical issue giving the advantages and Independent disadvantages of various options.

\section{C1}

Can understand a wide range of demanding, longer texts, and recognize implicit meaning. Can express him/herself fluently and spontaneously without 
much obvious searching for expressions. Can use language flexibly and effectively for social, academic and professional purposes. Can produce clear, well-structured, detailed text on complex subjects, showing controlled use of organizational patterns, connectors and cohesive devices.

\section{C2}

Can understand with ease virtually everything heard or read. Can summarize information from different spoken and written sources, reconstructing arguments and accounts in a coherent presentation. Can express him/herself spontaneously, very fluently and precisely, differentiating finer shades of meaning even in more complex situations.

The TOPIK also consists of 6 grades, as CEFR. In addition, general measures of both tests are also very similar. Grades of TOPIK are briefly explained in the following (TOPIK, 2016):

\section{1 st grade}

Able to carry out basic conversations related to daily surviving skills such as self-introduction, purchasing, ordering food, etc., and understand the contents related to very personal and familiar subjects such as himself/ herself, family, hobby, weather and the like. Able to create simple sentences based on about 800 words of basic vocabulary and possess understanding of basic grammar. It is equal to Al level, which is to understand and compose simple and useful sentences related to everyday life.

\section{2nd grade}

Able to carry out simple conversations related to daily routines such as making phone calls and asking for a favor, as well as using public facilities in daily life. Able to use about 1,500 to 2,000 words and understand personal and familiar subjects in certain order, join into paragraphs. Able to use formal and informal expressions according to the situation.

\section{3rd grade}

Able to perform basic linguistic functions, necessary to use various public facilities and maintain social relationship, not experiencing significant difficulty in routine life. Able to understand and speak on social or some specific topics familiar to himself/herself. Able to understand and use the written language and spoken language based on their distinctive basic characteristics.

\section{4th grade}

Able to perform linguistic function, necessary to use various public facilities and maintain social relationship, and carry out the function to the degree which is necessary for the performance of ordinary works. Able to understand easy parts in news broadcasts, newspapers, understand and use the expressions related to social and abstract subjects relatively correctly and fluently. Able to understand social and cultural subjects, based on the understanding of Korean culture and frequently used idiomatic expressions.

\section{5th grade}

Able to perform linguistic function to the degree which is necessary for research and works in professional fields. Able to understand and use the 
expressions related to even unfamiliar aspects of politics, economics, society, and culture. Able to use the expressions properly, depending on formal, informal, spoken/written context.

\section{6th grade}

Able to perform linguistic function necessary to the research and works in professional fields relatively correctly and fluently. Able to understand and use the expressions related to even unfamiliar subjects of politics, economics, society, and culture. Experience no difficulty in performing the functions or conveying the meaning, although the proficiency has not reached full native speaker proficiency.

CEFR and TOPIK suggest how to take advantages of this measure in teaching and learning evaluation with these general criteria of each level in step-by-step measures of language proficiency in communicative situation, theme, grammar, vocabulary and functions described in detail by language and behavior.

As was stated above, the TOPIK is similarly divided into the levels according to the standards of the CEFR. However, the foreign language education in Korea is still very different from the CEFR. Here we briefly analyze the foreign language education in Korea, and in the next chapter, we will look at the evaluation methods and standards of the CEFR and TOPIK.

In order to establish the direction of the overall foreign language education in Korea, we try to compare some elements. Considering the number of different environments, we exclude educational goals of political and social environment and national level. We present the direction of development and compare the foreign language course of Korean high schools to A1, a basic step of language courses.

First, we will look at the overall measure. CEFR presents the step-by-step levels that are very simple sentences and familiar everyday expressions aimed to meet the specific needs. In addition, the learners can introduce themselves and others and ask others about personal details (for example, where they live, who they know, what kind of stuff they have and etc.). The learners should be able to answer these kinds of questions and communicate in a simple and explicit way when the partners of conversation speak slowly and clearly on purpose. To find out whether the learners reach the level, the selfdiagnosis and the qualitative aspects of usage of spoken language are made.

\section{* Self-diagnosis}

Listening: If the speaker speaks slowly and clearly, you can understand familiar words and simple sentences related to the specific things about yourself, your family or surroundings.

Reading: For example, you can understand signs or posters, familiar names in the products of catalogues, words, and simple sentences. 
Dialogue: If the conversation partner speaks slowly, repeating or replacing complicated words with more simple ones, is ready to help you express, then you can have a brief conversation. You can ask a simple question and answer understandably and relevantly to the topic of conversation.

Monologue: You can talk about 'who you know' or 'where they live' using simple phrases and sentences.

Writing: You can write a short, simple text on a postcard (e.g. greetings). You are able to write name, address, nationality, and etc. on the paper form.

\section{* The qualitative aspects of the usage of spoken language}

Range: You know the vocabulary and grammar of a very limited repertoire related to the private and specific individual circumstances.

Suitability: You can use simple and memorized grammatical structures and sentence patterns in only a few limited situations.

Fluency: You can use very short and isolated expressions. You may take time to find an expression, to point out a bit less familiar words, or to solve the communication problem.

Interactions: You can ask and answer about personal details. You can communicate in a simple way, but the communication is done slowly by repeating, changing or correcting words.

Cohesion: You can use conjunctions such as 'and' and 'why' to connect the words.

Curriculum of foreign language in Korea is different to that of CERF. First of all, a fundamental difference can be seen in the goal of language education. While the language education goal in European countries, focused on life situations, is the direct communication, the Korean goal is rather abstract. Learners can acquire basic German expressions to use (Globaniat et al. 2003 , p.18), but as they do not have a specific goal of studying German, they remain with abstract knowledge.

In addition, there is a difference in classifying the linguistic function. While CEFR classifies the language activity into acceptance, production, exchange, and mediation, the Korean curriculum classifies it into listening, speaking, reading, and writing (Davies et al. 1999).

Lastly, while CEFR sees the language as a starting point and classifies the cultural content as a comprehensive assignment, Korean curriculum aims for direct understanding of the culture of German-speaking countries. It even mentions about understanding the nature of culture, recognizing the cultural value, and comprehending the universality and specialty of culture through the cultural comparison (Weekly, October 18. 2015).

There are differences in the context of the use of language. Therefore, the chosen living area should be able to motivate learners, as for the adult education, it should coincide with the advantage of the institution supporting the linguistic process. Therefore, the language learning is limited to private, 
public, occupational, and educational area, and is setting the minimum requirements for the class. Several situations come out as the subordinate. The time and place that the conversation occurs, institution or organization, conversational participants, surrounding objects, occurring events, language use by speakers, and language situation-related texts should come out. Therefore, the following situation is being presented specifically as the relevant use of the context:

Places: Home (e.g. House, Room, Garden), School dormitory, Hotel accommodation, Countryside, Beaches

Organizations: Family, Social Network

Person: Parents, Children, Siblings, Parents of brothers and sisters, Nieces, Nephews, Parents-in-law, Friends, Relatives

Goods: Equipment, Furniture, Housewares, Hygiene items, Animals, Trees, Plants, Household goods, Handbags, Leisure goods, Sports goods, Clothes, Toys, Tools, Artworks, Books

Events: Family feast, Contingency, Festival, Visiting, Meeting, Nature, Walking, Biking, Driving cars, Vacations, Picnics, Sports events

Doing: Daily life, Taking on and off clothes, Cooking, Eating, Washing, Chores, Assembling, Gardening, Reading, Listening to radio, Watching television, Recreational activities, Hobbies, Sports activities, Playing

Text: Fax, Recipes, Fiction, Advertising, Personal letters, Giving and receiving oral text, Warranty, Guide books, Magazines, Newspapers, Pamphlets

The educational curriculum of Korea is classified as the external context with cultural content. It is presented within the context of everyday culture: Social customs include Greeting and Introduction (Greetings, Asking about the safety, Introducing myself and others, Addressing correctly), Private and Family life (Family relationships, Communication of family members, Daily routine), School life (Courses, Classes, Teachers, Companionship, School run, Extracurricular activities), Hobbies and Recreational activities (Sports, Music, Dancing, Reading, Computer games), Daily life (Food, Clothing and Shelter, Buying things, Weather, Health and medical care), Customs (Invitation and visit, Gift, Promise, Goodbye, Conversation, Behavior), Travel, Transportation, Communication means (Transportation, Accommodation, Buying tickets, Travel, Directions). Social context are Living Culture (Table manners, Etiquette, Housing, Clothing, Visiting public office), Cultural institutions (Politics, Economy, Society, Education, Welfare, Health care, Media, Sports, Environmental protection, Telecommunications), History and Geography (Ethnicity, Values, Tourist attractions, Celebrities, The European Union, Division and reunification, Nazism and the Jews), Arts and culture (Music, Arts, Theater, Opera, Festivals, Cultural heritage), Language and Culture (Name, Proverbs, Gestures, Terminology, Symbols and Parables, Literature). 


\section{Evaluation criteria of CEFR and TOPIK}

European languages, English, German, French, Spanish, Italian, and Portuguese when comparing the assessment tool based on the system of the CEFR as follows.

\begin{tabular}{|c|c|c|c|c|c|c|c|}
\hline L & 0 & A1 & A2 & B1 & B2 & C1 & C2 \\
\hline$E$ & $\begin{array}{l}\text { Cambridge } \\
\text { English } \\
\text { Language } \\
\text { Assessment }\end{array}$ & $\begin{array}{l}\text { Cambridge } \\
\text { English: } \\
\text { Starters }\end{array}$ & $\begin{array}{l}\text { Cambridge } \\
\text { English: } \\
\text { Movers }\end{array}$ & $\begin{array}{l}\text { Cambridge } \\
\text { English: } \\
\text { Flyers }\end{array}$ & $\begin{array}{l}\text { Cambridge } \\
\text { English: } \\
\text { Business } \\
\text { Preliminary }\end{array}$ & $\begin{array}{l}\text { Cambridge } \\
\text { English: } \\
\text { Business } \\
\text { Vantage }\end{array}$ & \\
\hline $\mathbf{F}$ & CIEP & \multicolumn{6}{|c|}{$\begin{array}{c}\text { Test de connaissance du franVantagena } \\
\text { - TCF-TP } \\
\text { - TCF-DAP } \\
\text { - TCF-QuPon } \\
\text { - TCF-ANF }\end{array}$} \\
\hline G & $\begin{array}{l}\text { Goethe- } \\
\text { Institut }\end{array}$ & $\begin{array}{c}\text { Goethe } \\
\text { Zertfikat A1 } \\
\text { Start Deutsch } \\
1\end{array}$ & $\begin{array}{c}\text { Goethe } \\
\text { Zertifikat A2 } \\
\text { Start Deutsch } \\
2\end{array}$ & $\begin{array}{c}\text { Goethe } \\
\text { Zertifikat B1 }\end{array}$ & $\begin{array}{c}\text { Goethe- } \\
\text { Zertifikat B2 }\end{array}$ & $\begin{array}{c}\text { Goethe- } \\
\text { Zertifikat C1 }\end{array}$ & $\begin{array}{l}\text { Goethe- } \\
\text { Zertifikat C2: } \\
\text { Grot Deutsch } \\
\text { 2aryench, } \\
\text { Spanis }\end{array}$ \\
\hline I & $\begin{array}{l}\text { University } \\
\quad \text { for } \\
\text { Foreigners } \\
\text { Perugia }\end{array}$ & & CELI 1 & CELI 2 & CELI 3 & CELI 4 & CELI 5 \\
\hline $\mathbf{P}$ & CAPLE & & $\begin{array}{l}\text { Certificad ol- } \\
\text { nicial de Por- } \\
\text { tugugi ahgua } \\
\text { Estrangeira } \\
\text { (CIPLE ) }\end{array}$ & $\begin{array}{c}\text { Diploma El- } \\
\text { ementar de } \\
\text { Portugugu } \\
\text { giahgua } \\
\text { Estrangeira } \\
\text { (CIPL) }\end{array}$ & $\begin{array}{c}\text { Diploma } \\
\text { Intermtar de } \\
\text { Portugugu } \\
\text { giahgua Es- } \\
\text { trangeira } \\
\text { (CIPL) }\end{array}$ & $\begin{array}{c}\text { Diploma } \\
\text { Avanrmtar } \\
\text { de Portugugu } \\
\text { giahguaEs } \\
\text { trangeira }(\mathrm{Cl})\end{array}$ & $\begin{array}{l}\text { Diploma } \\
\text { Universit de } \\
\text { Portugugu } \\
\text { giahgua } \\
\text { Estrangeira } \\
\text { (CIPLE ) }\end{array}$ \\
\hline
\end{tabular}

$<$ Table 2> Evaluation System of the major European countries (ALTE Framework, 2015) $\mathrm{E}($ English), F(French), G(German), I(Italian), P(Portuguese)

Among the above cases of several countries, let us compare the type of test of Goethe Zertfikat in Germany and TOPIK in Korea. The Goethe Institute is a public agency of the German Government where German is taught as a foreign language. It has been providing German courses since it was founded in 1951. Goethe Zertfikat has been granted to a variety of participants from 1962. Creation and implementation of assessment tools of German as a foreign language is largely composed of following the same procedures. First step is to create a draft of test. The experienced professional test writers in that learning phase create a task draft and request for review to the test editorial department. Second step is to simulate assessment. A mock test is conducted in domestic and foreign Goethe-Institut which is targeted for 200 candidates. In addition, the task is complemented or replaced by analyzing the results of the mock test. The test data is stored in the item pool and then reused for later. Third 
step is to conduct the test. It is performed by the Goethe Institute around the world in consultation with headquarters. Fourth step is to score and valuate the test. Scoring and valuation is conducted by two local examiners who trained supervision. After then, detailed grading scale is proposed. The test results are presented with scores and grades in the certificate. Goethe Zertifikat is also carried out in accordance with this procedure which is divided into 6 grades according to the guidelines of the Common European Framework of Reference. Each grade is composed of the four modules: listening, reading, writing and speaking. In written test 65 minutes are provided for reading part, about 40 minutes for listening part, and 60 minutes for the writing part. Typically, speaking modules are conducted 2 -in-1 team, and exceptions are possible as in the individual tests. The test time of 2-in-1 team is 15 minutes while the one of individual is 10 minutes. The oral test preparation time for 2-in-1 team and individual is 15 minutes.

Tests are commonly started with the reading modules. The candidates copy their answers into the answer sheet after marking their test materials. Candidates must allocate approximately five minutes within the test time to copy their answers to answer sheet.

After the reading part is finished, the listening test takes place. The examiner plays the voice recorder. Candidates write down the answer on the candidate's materials for a start and write down the answers on the listening answer sheet later. Candidates have about five minutes to copy their answers to the answer sheet.

Then candidates continue to the task of writing module. Candidates should write down the text directly on the answer sheet. If candidates write down the text in the note paper, they should plan enough time to copy the text in the answer sheet within the test time.

In the speaking module, it takes about 1 minute to introduce the beginning dialogue, which includes the introduction of examiners and candidates. Task 1 approximately takes 2-3 minutes, Task 2 takes about 3-4 minutes, and Task 3 takes about 1-2 minutes depending on candidates. The total test time is about 15 minutes (2-in-1 team) and 10 minutes (individual). Speaking module is conducted by two examiners. One examiner is in charge of dialogs. Another examiner asks questions in Task 3. Two examiners note and mark the test with independent results. When starting the test, examiners briefly greet the candidate and introduce themselves. One examiner has a short talk with candidates. Examiners explain the task briefly prior to the start of the entire examination. The candidates plan the task together in Task 1 (in the case of an individual test, the candidate plan the task with the examiner). The two candidates will present their suggestions and opinions. They announce the topic in turn in Task 2. They introduce the topic, explain their notions, talk about the pros and cons, and finish their announcement (in the individual test, the candidate talks only). In Task 3, the two candidates are asked questions 
by the two examiners about the presentation they made in Task 2 . Each candidate answers their questions.

The speaking module may acquire a maximum of 100 points those are 28 points of the Task 1, 40 points of the Task 2, 16 points of the Task 3, and 16 points in the pronunciation. Introduction is not reflected in the point rating.

There are 30 questions in the reading module. The measuring point for each question is 1 . One measuring point and one answer are given 1 point or 0 point. The total score is converted into 100 as the basis point. The obtained points multiply 3.33 and round-off to the measuring point.

There are 30 questions in the listening module. Each question is one measuring point. One measurement point is given 1 point or 0 point. The total score is converted into the resulting point of 100. Similarly, the obtained points multiply 3.33 and round-off to the measuring point.

The writing modules are graded according to scoring criteria, and two appointed scorers grade the points independently. (Refer to the resources section of the exercise test data set). Scores can be given only specified points in each standard. Middle scores are not allowed. Scoring associated with incorrect answers and etc. can be recorded in answer sheet. In the writing module, it can be earned up to 100 points. It is only awarded the predetermined points for each of the criteria; intermediate points are not permitted. Scoring is based on the copied answer on the answer sheet. The score of scorer 1 and scorer 2 are copied to the writing result recording paper. Total scores of the two scorers' are calculated to the arithmetic average and rounded up to the nearest whole number. In the writing module, the score of scorer 1 is below the passing grade or if the arithmetic average of the scorer 1 and scorer 2 is less than 60 points, then the third scorer (= scorers 3 ) score it again. Scoring results are written in the results recording paper. Correct calculation of the resulting paper is then checked and signed by one of scorers.

As for the beginner level of TOPIK, in the previous tests the evaluation was done in 4 parts: vocabulary and grammar, writing, listening, and reading. But in the recently reorganized test, both vocabulary grammar and writing are included in the reading part and the writing part has been abolished. Therefore, now the evaluation is done only in 2 parts: listening and reading. Also, the intermediate and advanced levels, that used to be separate, were connected to be defined as TOPIK $\Pi$, and existing separate vocabulary and grammar part of the test was abolished like in the beginner level. Therefore, the evaluation was done only in 3 parts: listening, reading, and writing.

In the reorganized test, the number of questions is changed, too. As the questions were divided into 2 parts, TOPIK I and $\Pi$, in the existing 3-level division, the number of questions was also changed. As for the beginner level, the total number of questions in the former test was 106: 30 questions of vocabulary and grammar, 30 questions of reading, 30 questions of listening, and 16 questions of writing. In the reorganized test, 
the total number of questions became 70 : reading part of 40 questions and listening part of 30 questions as the vocabulary and grammar part together with writing part were abolished and incorporated into the reading part. Accordingly, the number of questions was reduced and as the writing part was abolished, the subjective questions and writing questions disappeared from the beginner level.

Unlike the existing test that was divided into intermediate level and advanced level, in the reorganized test, where both levels are combined, the number of questions of the intermediate and advanced level varied largely. In the existing test, vocabulary and grammar, listening, and reading each have 30 questions; the writing part of intermediate level has 15 and that of the advanced level 14 questions. The total number of questions in intermediate level is 105 , ant that of the advanced level is 104 . However, in the reorganized test, the vocabulary and grammar part and the reading part were integrated to make 50 questions. As for the writing part, all of the multiple choice questions disappeared and it consists of total 4 questions including the short and long sentence writing. The number of questions of listening part increased to 50. Therefore, the number of questions of the intermediate and advanced levels is total to 104, but the entire number of questions is hardly changed. To sum up again, we can summarize as follows:

The TOPIK I consists of 30 questions of listening part, 40 questions of reading part, and 70 multiple-choice questions. TOPIK $\Pi$ consists of 50 multiple-choice questions of listening test, the writing test on two-sentences, one short and one long writing test. In TOPIK $\Pi 50$ multiple-choice questions in the listening part, writing two sentences in the writing part, one short-writing, and one long-writing question. Here, in reading part 50 multiplechoice questions, and all combined is 104 questions. Each part is totaling up as 100 points as a full mark, TOPIK I is 200 points as a full mark, and TOPIK $\Pi$ is 300 points as a full mark.

If in TOPIK I examinee collects more than 80 points, he/she is given the first grade. If he/she earns more than 120 points, the second grade is given. In case of TOPIK $I$, if the examinee earns more than 120 points the third grade is given, if more than 150 points, the fourth grade, and 190 points or more leads to the fifth grade. For more than 230 points, the sixth grade is given. Until the 34th Test, each part had a failing course, but now it has changed so that failing is nearly eliminated and the grade is given based on the total score (TOPIK, 2015). 


\begin{tabular}{|c|c|c|c|}
\hline Level & Grade & Part \& Question Number & $\begin{array}{l}\text { A passing score } \\
\text { (total score based) }\end{array}$ \\
\hline \multirow{4}{*}{ TOPIK II } & 6 th grade & \multirow{4}{*}{$\begin{array}{c}\text { Listening(Multiple choice } 50 \text { ) } \\
\text { Writing(Sentence writing 2, Short } \\
\text { sentence writing 1, Long sentence } \\
\text { writing 1) } \\
\text { Reading(Multiple choice 50) }\end{array}$} & More than 230points/300 \\
\hline & 5 th grade & & More than 190points /300 \\
\hline & 4 th grade & & More than 150points /300 \\
\hline & 3rd grade & & More than 120points / 300 \\
\hline \multirow{2}{*}{ TOPIK I } & 2nd grade & \multirow{2}{*}{$\begin{array}{l}\text { Listening(Multiple choice 30) } \\
\text { Reading(Multiple choice 40) }\end{array}$} & More than 140points /200 \\
\hline & 1st grade & & More than 80points /200 \\
\hline
\end{tabular}

$<$ Table $3>$ Level and test area of TOPIK

\section{Question types of TOPIK}

The TOPIK does not include a separate test of vocabulary or grammar parts. Vocabulary and grammar skills are to be verified in the reading and writing parts. Thus, here we will look at question types of listening, reading and writing.

The important theoretical starting point in the creation of a general evaluation tool is ability to communicate in the language model of Bachman and Palmer (1996). According to the model bellow, communication skills are based on planning knowledge and pragmatic knowledge such as $<$ table $4>$.

\begin{tabular}{|c|c|c|c|}
\hline \multicolumn{2}{|c|}{ Planning knowledge } & \multicolumn{2}{|c|}{ Pragmatic knowledge } \\
\hline $\begin{array}{l}\text { Grammatical } \\
\text { knowledge }\end{array}$ & Text knowledge & Functional knowledge & Sociolinguistic knowledge \\
\hline $\begin{array}{l}\text { Vocabulary } \\
\text { Syntax } \\
\text { Form } \\
\text { Orthography } \\
\text { Pronunciation } \\
\text { Accent }\end{array}$ & $\begin{array}{l}\text { Rhetorical Planning } \\
\text { Cohesion }\end{array}$ & $\begin{array}{l}\text { Recognition } \\
\text { preference } \\
\text { Operation } \\
\text { Discovery } \\
\text { Creativity }\end{array}$ & $\begin{array}{c}\text { Custom of language } \\
\text { Dialect } \\
\text { Groups languages } \\
\text { Naturalness }\end{array}$ \\
\hline
\end{tabular}

$<$ Table 4> The model of communication skills Bachman \& Palmer (1996)

It is evaluated by passive grammar and lexical knowledge in the reading and the listening, active grammar and lexical knowledge in the writing that are considered expression, accuracy, etc. of scoring items. Text knowledge evaluated by understanding of the structure of the text from the reading and listening parts, as well as classifying the critical information and non- critical information and taking advantage of understanding strategy on the text type. Text and discourse are to be made according to the communication situation in the writing part, the composition of the text, cohesion are in scoring items. 
The communicative function of language expression is understood by functional knowledge, and it is evaluated by the ability to produce expression of compliance beyond the accuracy.

Sociolinguistic knowledge is tested if it is consistent with the communication situation and the conversational state, if the everyday idioms are understood, which is evaluated by the ability to understand the cultural context. 'Expression' is the subject of consideration in the scoring of the writing.

\begin{tabular}{|c|c|c|c|}
\hline \multicolumn{2}{|c|}{ Planning knowledge } & \multicolumn{2}{c|}{ Pragmatic knowledge } \\
\hline Grammatical knowledge & Text knowledge & Functional knowledge & $\begin{array}{c}\text { Sociolinguistic } \\
\text { knowledge }\end{array}$ \\
\hline $\begin{array}{c}\text { All areas, especially } \\
\text { reading and writing } \\
\text { (accuracy, expression) }\end{array}$ & $\begin{array}{c}\text { Reading and listening } \\
\text { (passive) } \\
\text { Writing (text } \\
\text { composition, cohesion) }\end{array}$ & $\begin{array}{c}\text { Reading, listening } \\
\text { (expression) }\end{array}$ & $\begin{array}{c}\text { In particular, writing } \\
\text { (expression) }\end{array}$ \\
\hline
\end{tabular}

$<$ Table 5>Evaluation Criteria of communication skills Bachman \&Palmer (1996)

\section{Listening}

The listening part did not change significantly in intermediate and advanced level. It almost did not change the type of questions, except one. However, there have not been presented marking of the given objects and 'Finding titles' in intermediate and advanced grade which was proposed in the beginner grade.

\section{(1) Vocabulary listening}

The questions assess whether the examinees heard the words of the core content. It involves listening to numbers or particular key words. The method is proposed of selecting multiple choice questions.

\section{(2) Listening to topics and key points}

The evaluation types to find the key content after listening to conversations, monologues, etc. For example, the questions are asked to find where the dialogue or the discourse happens, the key idea, topic, etc., through multiple choice types. These types of questions are presented in the beginner level as 1 question, in the intermediate and the advanced level 9 questions are presented.

\section{(3) Deductive listening}

The types of questions where the answers are inferred on the basis of information about the contents that is seemingly invisible. Also, the examinees infer the further contents from the discourse markers or the whole content. For example, to guess the next situation after listening to the conversation, thoughts, intentions of speaker, etc. In the beginner level it is not presented, but in the intermediate and the advanced level 8 questions are presented.

\section{(4) Distinguishing discourse type}


The questions that require you to understand the features and functions of the type of information heard. It can be deduced from the discourse contents through a variety of factors, to distinguish the types of discourse. This type is not presented in the intermediate and advanced and it only appears 1 question in the beginner level.

\section{(5) Finding pictures or materials}

These are the question types that require finding appropriate pictures or materials after hearing the content. These types of questions can be found in all of the beginner, intermediate, and advanced levels.

\section{Writing}

TOPIK test is reorganized from the 35 th test in 2014, and the most changed part is the writing part. There was the writing test in the beginner level in the previous test, but writing test is only presented for the advanced level after 35 th test. The following is the scoring methods and types of questions in writing part:

\begin{tabular}{|c|c|c|}
\hline Questions & Evaluation Category & Evaluation Details \\
\hline \multirow{2}{*}{$51-52$} & $\begin{array}{l}\text { Content and task } \\
\text { execution }\end{array}$ & Are the written contents suitable for the presented task? \\
\hline & Use of language & Are the vocabulary, words, etc., correct? \\
\hline \multirow{3}{*}{$53-54$} & $\begin{array}{l}\text { Content and task } \\
\text { execution }\end{array}$ & $\begin{array}{l}\text { Has the given task been performed adequately? } \\
\text { Is the related writing rich in content and being constructed in a } \\
\text { diversified way? }\end{array}$ \\
\hline & $\begin{array}{l}\text { Development } \\
\text { structure }\end{array}$ & $\begin{array}{l}\text { Is the wring structure clear, logistic, and conveying the key idea } \\
\quad \text { well? } \\
\begin{array}{c}\text { Was the discourse cover used properly which is helpful for the } \\
\text { development of logic? }\end{array}\end{array}$ \\
\hline & Use of language & $\begin{array}{l}\text { Were the vocabulary, grammar, etc., used correctly and in a } \\
\text { diversified way? } \\
\text { Does the writing suit the purpose and function according to } \\
\text { formalities? }\end{array}$ \\
\hline
\end{tabular}

$<$ Table 6> Evaluation of writing part

The existing types of TOPIK that disappeared from the reform of the test are multiple-choice questions such as 'arranging word order', 'connecting sentence', 'changing writing', and 'completing dialog'. Those are not multiplechoice questions and no matter if the articles are long or short all articles of the writing part should be filled in.

\section{(1) Filling in the blanks}

The task requires filling in the blanks in the conversation. This type may be found in the reading part, where all questions have to be answered from 
multiple choices, but the writing part is different, because it is required to actually write an article. The examination guidelines say that you need to use proper vocabulary and grammar for each level in the answer sheet. In the intermediate and the advanced level two questions are presented in the writing part.

\section{(2) Writing using materials}

In this task after looking at the presented materials one has to summarize or write one's views. It is mainly presented in the form of short writing, where advantages or disadvantages, the pros and cons views have to be expressed with proper sentences. The length of article is between 200 and 300 characters. There is 1 question in the intermediate and the advanced level.

\section{(3) Writing depending on the title}

In this task the examinees are given titles of the article that they have to write themselves. They are also presented some information that should be included. The length of article is 600 characters. 1 question is presented in the intermediate and the advanced level.

\section{Reading}

There is no separate part of vocabulary and grammar in TOPIK. Reading part includes a question of vocabulary and grammar parts. Including those, the following is classification of the questions:

\section{(1) Finding common words}

This type of question is presented frequently the in beginner level. After reading a number of words, find a common word and put the most suitable words of the same category in the blank.

\section{(2) Finding the correct sentence}

The questions that require you to put an answer in the suggested sentences, because this part does not deal with the grammar part separately. It presents different endings in the same words, you should choose carefully the most appropriate words.

\section{(3) Interpreting meanings after reading the title}

This type of questions requires you to find related paragraphs or sentences after reading the titles in the newspapers or books. In the beginner level this type is not presented, only 3 questions are presented in the intermediate and advanced level.

\section{(4) Finding vocabulary and discourse markers}

The questions that require you to understand the information presented in the article and find the vocabulary and phrase, discourse marker in the blank. The 12 questions are presented in the intermediate and advanced level, 7 questions are presented in the beginner level.

\section{(5) Grasping the information}


The questions that require you to assess whether you understand the information in the notices, advertisements, user manuals, contracts, etc., the actual reading materials. The 6 questions are presented in the intermediate and advanced level, 3 questions are presented in the beginner level.

\section{(6) Grasping main ideas and themes}

The questions that require you to read the article and understand the topic and main idea. 6 questions are presented in the intermediate and advanced level, 3 questions are presented in the beginner level. The question is: Choose the appropriate subject of the next article.

\section{(7) Arranging the order by paragraphs}

The questions require you to understand the relations between paragraphs after reading them. It is mainly presented in the form, arranged to fit into a sequence. There are 2 questions in the beginner level, and 3 questions in the intermediate and advanced level.

\section{(8) Grasping the function or purpose of the article}

The questions that require you to grasp what the function or purpose of the article is after reading it. Each of levels asks 1 question.

\section{(9) Grasping the attitude and tone of the author}

The questions that require you to read the article and interpret the type of attitude and tone of the author. Underline the statement that shows the attitude of the author. In the beginner level it does not appear, while there are 2 questions in the intermediate and advanced level.

\section{(10) Inserting the sentence}

It tests whether you read the article logically. The certain statements are presented in the example parts and the examinees are asked to insert them into the most appropriate position. There is 1 question in the beginner level and 4 questions are in the intermediate and advanced level.

This ambiguity is still an issue for the criteria of TOPIK. The evaluation criteria of TOPIK are too vague and abstract to analyze the specific activity materials. The evaluation criteria of TOPIK are ambiguous and cause discrepancies between the reference and actual problems as well. The beginner level criteria are excessively high, and have a problem such that the evaluation criteria setting does not take into account of the situation of Korean language learner. This point remains to be still improved.

Although TOPIK has gone through several curriculum revisions, it has not had the curriculum that could evaluate all standards of achievements, goals, teaching, learning and etc. that are never-ending discussion about the domestic Korean language courses. That is the reason why TOPIK has become ambiguous about its evaluation criteria.

The Korean language courses reveal in detail of 'Examples of content elements' corresponding to the 'Achievement standards'. Specifically, it proposes 'the level and range of speech' of each part. It is quite materialized 
when simply comparing only to the achievement standards and the evaluation criteria of TOPIK.

As for TOPIK evaluation standards, the 'level and scope of discourse' should be presented like a simple conversation expressing one's emotion in daily life and a simple story showing the order of incidents clearly to describe specified contents with which one needs to deal. Also, the examples of content elements which will complement the obscure and ambiguous achievement standards need to be presented specifically such as 'apprehending characters appearing in the story' and 'expressing the imagined figure as a drawing'. If TOPIK evaluation standards are specified like this, the appropriateness, clarity, and communication possibility of Korean language textbook will be improved more than now, and its contents or questions will be less likely be too difficult or obscure.

Since TOPIK is the proficiency evaluation, it is different from the achievement evaluation which is directly related to the educational purpose or class contents of certain institution. However, the proficiency evaluation is a tool that measures students' knowledge on what they can do in their real life by using the goal of language. Given that today's trend of Korean language education and textbook being focused on the communication, there is a need to raise the connectivity between the Korean language textbook and the TOPIK evaluation standards. In this sense, if TOPIK evaluation standards and questions become more specified, Korean language learners who learned Korean language through the Korean language textbook will be able to learn more exactly and properly. It is expected to help with the real communication as well as Korean language learners' results at TOPIK.

\section{Conclusion}

TOPIK is a test to measure and evaluate the Korean proficiency targeting for overseas Koreans and foreigners who do not speak Korean as their first language. According to October $6^{\text {th }}, 2015$ The Weekly Kyunghyang article, "number of applicants of TOPIK reached the highest level ever 208,448 in 2014. The trend of interest in the Korean language is more and more increasing." (Weekly, October 18. 2015). Increasing number of people learn Korean in China and Southeast Asia, as well as in Europe with the increase in interest in the TOPIK. This paper, according to these needs, compared TOPIK with the Common European Framework of Reference in terms of overall system, evaluation method, question types, and etc.

As in Europe, Korea also divides the language level into 6 grades. It prepares the evaluation criteria for each level. But the problem lies in the lack of speaking test in TOPIK. In order to understand the language proficiency of the person, speaking, listening, reading and writing in all areas should be evaluated, yet, there is no speaking test, and it is unfortunate that there 
is no writing test in the beginner level. This is what should be improved in the future.

European countries autonomously take a language test, which is the big framework in the Common European Framework of Reference. For example, in Germany, the Goethe Institute is in charge of the German language test and issues accredited language skills certificate. In South Korea, the National Institute for International Education is in charge of TOPIK and test is held four times during the year in Korea and overseas.

I hope this paper will be a great help for the future of Korean learners who are interested in the Korean language and take TOPIK.

\section{References}

\section{a) Books}

Bachman, L., \& Palmer, A. S., 1996. Language testing in practice. Oxford: Oxford University Press.

Davies, A., Brown, A., Elder, C., Hill, K., Lumley, T., \& McNamara, T. 1999. Dictionary of language testing. Cambridge: University of Cambridge Local Examinations Syndicate.

Globaniat et al. 2003. Profile deutsch Lernzielbestimmungen Kannbeschreibungen Kommunikative Mittel Niveau A1, A2, B1, B2, Langenscheidt.

\section{b) Articles}

Lee, Wonkyung, 2007. Validation system of German as a foreign language based on the CEFR, Teaching Korean as a Foreign Language, 32, pp.29-42.

Yang, Dowon, 2009. Der Gemeisame eurooDeche Referenzrahmen und das Koreanische Curruculum, Korean Journal of Teacher Education 25(1), pp.142-156.

\section{c) Documents without Authors}

Council of Europe, 1997.Common European Framework of Reference For Languages: Learning, Teaching, Assessment. Language Policy Unit, Strasbourg.

\section{d) Online resources}

TOPIK. Test of Proficiency in Korean, n.d. About the TOPIK. [online] Available at: $<$ http://www.topik.go.kr/usr/cmm/subLocation.do?menuSeq=2210101\#none> [Accessed 23January 2016].

The Weely Kyunghyang. Available at: $<$ http://weekly.khan.co.kr/khnm.html?mode=vi ew\&code $=115 \&$ artid $=201502171037361 \& \mathrm{pt}=\mathrm{nv}>$ [Accessed 23January 2016].

Association of Language Teachers in Europe, 2015. ALTE Framework 2015. Available at: $<$ http://www.alte.org/attachments/pdfs/files/2015_05_26_alte_framework_v12_ ayjp1.pdf> [Accessed 23 January 2016]. 


\section{About Author}

\section{Yunhee WON}

She is an instructor of Pusan National University, South Korea. She received ph. D. in German Literature and Korean Education. She lectures on German Literature, language and Korean Media Culture. She also teaches Korean Language Education. Her research interests are German language education, Korean language education as a foreign language. Her representative works are A Case Study on Interlanguage of German Korean Beginners (a doctoral thesis; 2010), Easy to learn German Grammar (Pusan National University Press; 2012), A Study on Language and Culture Learning Program between Korea and Germany (2013).

wonyunhee@daum.net 